\title{
A Comprehensive Estimation of the Economic Effects of Meteorological Services Based on the Input-Output Method
}

\author{
Xianhua Wu, ${ }^{1,2}$ Guo Wei, ${ }^{3}$ Lingjuan Yang, ${ }^{1,2}$ Ji Guo, ${ }^{1,2}$ Huaguo Lu, ${ }^{4}$ \\ Yunfeng Chen, ${ }^{5}$ and Jian Sun ${ }^{6}$ \\ ${ }^{1}$ Collaborative Innovation Center on Forecast and Evaluation of Meteorological Disasters, \\ Nanjing University of Information Science \& Technology, Nanjing, Jiangsu 210044, China \\ ${ }^{2}$ School of Economics and Management, Nanjing University of Information Science and Technology, Nanjing, Jiangsu 210044, China \\ ${ }^{3}$ Department of Mathematics \& Computer Science, University of North Carolina at Pembroke, Pembroke, NC 28372, USA \\ ${ }^{4}$ School of Languages and Cultures, Nanjing University of Information Science and Technology, Nanjing, Jiangsu 210044, China \\ ${ }^{5}$ Popular Science Propaganda Center, China Meteorological Administration, Beijing 100081, China \\ ${ }^{6}$ Public Meteorological Service Center, China Meteorological Administration, Beijing 100081, China
}

Correspondence should be addressed to Xianhua Wu; wxhua_77@nuist.edu.cn

Received 30 August 2013; Accepted 12 October 2013; Published 21 January 2014

Academic Editors: J. Corte-Real and J. Liu

Copyright (C) 2014 Xianhua Wu et al. This is an open access article distributed under the Creative Commons Attribution License, which permits unrestricted use, distribution, and reproduction in any medium, provided the original work is properly cited.

\begin{abstract}
Concentrating on consuming coefficient, partition coefficient, and Leontief inverse matrix, relevant concepts and algorithms are developed for estimating the impact of meteorological services including the associated (indirect, complete) economic effect. Subsequently, quantitative estimations are particularly obtained for the meteorological services in Jiangxi province by utilizing the input-output method. It is found that the economic effects are noticeably rescued by the preventive strategies developed from both the meteorological information and internal relevance (interdependency) in the industrial economic system. Another finding is that the ratio range of input in the complete economic effect on meteorological services is about $1: 108.27-1: 183.06$, remarkably different from a previous estimation based on the Delphi method (1:30-1:51). Particularly, economic effects of meteorological services are higher for nontraditional users of manufacturing, wholesale and retail trades, services sector, tourism and culture, and art and lower for traditional users of agriculture, forestry, livestock, fishery, and construction industries.
\end{abstract}

\section{Introduction}

The production of sufficient food, fuel, and fiber to meet the world's needs in a sustainable manner relies not only on the natural resources for growing them but also critically upon favorable weather conditions [1]. In recent years, frequent severe weather conditions such as droughts, flood, heavy snowfalls, and high temperatures have increasingly raised governmental and public concerns about meteorological services. However, to promote the utilization of valuable meteorological services, benefits need to be demonstrated quantitatively and answers to relevant questions need to be convincible. Critical questions include those regarding the economic effects, their measures, and estimation methods and models. For example, what are some quantitative results regarding the economic effects saved from disastrous weathers due to accurate meteorological service forecasts? What are some meaningful and reasonable measures for estimating such benefits of meteorological services? Unfortunately, there have been no effective methods and models established in the literature that can be employed by scientists for the desired estimation of the economic effects attributable to meteorological services. One difficulty is to correctly identify the economic effects saved from meteorological services as they are associated with each link of production or consumption. Another difficulty is to determine the costs operating the whole process of meteorological services that requires a wide range of considerations, including weather forecasting systems and assessment of many indirect costs. Still another difficulty is to describe a practical demand function-the demands of 
meteorological services can be highly implicit at present. Moreover, highly demanded assessment methods and models of economic effects benefited from meteorological services are also related to assessment policies, processes, and practice $[2]$.

Attempts in overcoming these difficulties were proposed by many researchers. Studies and exploratory trials have been carried out for exploring effective technologies and solutions both in China and abroad. These solutions can be roughly classified into three categories: direct field investigation, expert knowledge and qualitative analysis, and inputoutput assessment. Among the methods in the direct field investigation category, the focus is to measure the effects on the service objects that are rescued due to the use of meteorological services for users through the direct field investigation. Nguyen et al. calculated the economic effects of typhoon warning services in Vietnam [3]. By designing questionnaires based on the contingent valuation method, Birol et al. estimated the economic effect of water resources management [4]. Within the second category, expert knowledge and qualitative analysis, one calculates the effect brought by meteorological services using expert knowledge, Delphi method, or alike and then combining qualitative analysis measures and quantitative analysis results. Krieger and Green put forward the decision and optimization model of service effect estimation [5]. Recently, Xu estimated meteorological service effects using the Delphi method [6]. Integrating the experts' knowledge into the epidemiology-based exposureresponse functions, Kan and Chen assessed the health based economic cost of particulate air pollution in urban areas of Shanghai of China [7]. For the third category, inputoutput assessment, researchers compute the associated effects brought by services using an input-output method. Chen and Yin proposed a computing method of indirect and complete economic effects [8]. Using input occupancy output techniques, Wang established an accounting method for estimating the complete forward and backward economic effects for all industries in the national economy [9]. Hewings and Sonis proposed some concepts and algorithms relating to forward and backward linkage, correlative relations within industries, and output multipliers in input-output analysis [10]. Recently, Chen et al. estimated the associated social economic effects brought by oyster breeding in Taiwan [11], and Kerschner and Hubacek assessed the potential economic effects of peak oil using the input-output analysis [12]. These are just some of the existing researches achieved so far.

The Delphi method (a structured communication technique, originally developed as a systematic, interactive forecasting method which relies on a panel of experts), is frequently employed by researchers. As a subjective, qualitative method, the Delphi method is essentially a feedback anonymous letter of inquiry method, with several advantages such as full role of experts, brainstorming, and high accuracy. However, it should be noticed that this expert opinion method can be utilized only when there is a lack of sufficient information-due to its drawbacks including (1) no clear criteria regarding expert selection, (2) lack of rigorous scientific analysis of the results, and (3) the final convergence of views having a tendency to follow the crowd.
Moreover, except for a few case studies, most researchers only estimated the direct effects without investigating the indirect effects, which results in a gap in the literature of meteorological services. Moreover, most researchers simply combined field investigations and expert knowledge for estimating service effects in a single region, industry or enterprise; few studies utilized the input-output method to estimate the comprehensive service effects. Research, using input-output methods to calculate the associated and indirect economic effects, is rare. Chen and Yin and Wang, respectively, defined the concepts of indirect economic effect and complete economic effect and put forward corresponding algorithms $[8,9]$.

Centered about consuming coefficients, partition coefficients and Leontief inverse matrix, we present in this paper the concepts of associated economic effect, indirect economic effect, and complete economic effect, input-output method, and algorithms that estimate, respectively, the associated, indirect, and complete economic effects. Generally, the direct economic effect is assumed to be known. In addition, illustrative examples are provided to explain the concepts and demonstrate the reliability and practicability of the models and algorithms regarding the theoretical innovation and economic effects for applications.

Specifically, since the input-output table reflects more accurately the technical and economic relationships between industries in the national economy [13], it has become an ideal tool for calculating the associated and indirect economic effects of industries. According to the principle of doing certain things and refraining from doing other things, we present assessment models for associated, indirect, and complete economic effects based on the input-output table. Taking the meteorological service data in Jiangxi province in 2007 as an example, we obtained a series of results regarding the economic effects of meteorological services.

Section 2 describes the concepts, principles, and hypotheses. Section 3 introduces our estimation methods and algorithms. Section 4 illustrates our methods and algorithm with an actual example. The last section, Section 5, lays out the concluding remarks.

\section{Concepts, Principles, and Hypotheses}

In this section we will define concepts that describe economic effects and then introduce the principle of input-output table and several hypotheses.

\footnotetext{
2.1. Definition of Concepts. Here we assume that the direct meteorological service object is industry $i$.

The direct economic effect of meteorological services is the increased economic effect due to the use of these meteorological services. To further explain this concept, assume that two similar industries, one utilizing the meteorological services and the other not, have similar input levels but with different outputs. The difference between the outputs that is beneficial from the use of the meteorological services is referred to as the direct economic effect.
} 
The associated economic effect of industry $i$ is the economic effect due to the demands of other industries for the products (or services) produced (or provided) by industry $i$, which is to be calculated through the interdependency coefficients.

The indirect economic effect of industry $i$ is the sum of economic effects for industry $i$ and other industries generated indirectly through an economic and technological relation.

The complete economic effect of industry $i$ is the increment of final output in all industries of national economy system brought by direct economic effect with the circulation of production-consumption.

2.2. Principle of the Input-Output Table. The input-output table describes resources of inputs and usages of outputs on all industries of the national economy in a matrix form for a period of time (usually one year). It reveals the quantitative relations which are not only interdependency but also mutually restraining for all industries of the national economy. As an important part of the national economic accounting system, the input-output table of China consists of three parts named as Quadrants I, II, and III. Table 1 is illustrated.

Interconnected, these three parts of input-output table fully and systematically reflect the interrelations of all industries of the national economy, during the production cycle process from production to usage, by view of total quantity and structure of input-output. The following are some basic balance relationships in the input-output table:

(i) line balance:

Intermediate use + Final use + Others

$$
=\text { Total output }+ \text { Inflow, }
$$

(ii) column balance:

Intermediate input + Increment $=$ Total input,

(iii) gross balance:

$$
\text { Total input }=\text { Total output }
$$

Total input in certain industry

$$
=\text { Total output in this industry }
$$

Total intermediate use $=$ Total Intermediate input,

(iv) interdependency between industries.

The interdependency between industries can be expressed as follows:

$$
x_{i}=\sum_{j}\left(a_{i j} x_{j}+c_{j}\right), \quad i=1,2, \ldots, n,
$$

or in the matrix form $X=A X+C$, where $x_{i}$ is the total output of industry $i, c_{i}$ is the final demand of industry $i$, and $a_{i j}$ is the ratio of the input of industry $i$ over the total demand of industry $j(1 \leq i, j \leq n)$. Given $n$ industries, $a_{i j}$ characterizes the distribution of inputs contributed by the $n$ industries $(i=1,2, \ldots, n)$ to the total input required by industry $j[15]$. Matrix $A$ will be called the technical coefficient matrix.
2.3. Hypotheses of Input-Output Model. The input-output model is a simplification of the Walrasian general equilibrium model [16]. There are three main hypotheses.

$H_{1}$ : Pure industry: assume that each industry only produces one kind of product with one production technology. Meanwhile no different production technology can be selected or mutually replaced in the process of production across different industries.

Models holding $H_{1}$ can reflect the composition of material consumption and the relation between production and technology more accurately.

$H_{2}$ : Each technical coefficient is relatively fixed. Regardless of factors of technical progress and increase of labor productivity, assume that each direct consumption coefficient (i.e., technical coefficient) $a_{i j}$ is fixed in a given period, that is to say, ignore influences of relevant dynamic factors.

Here, dynamic factors include change of time, technology, price, industry, or product structure among others. With $\mathrm{H}_{2}$, the analysis will be much simplified.

$\mathrm{H}_{3}$ : Linear relation: assume that there is a positive and proportional relationship between input and output in all industries of the national economy.

$\mathrm{H}_{3}$ is closely related to $\mathrm{H}_{2}$. On the premise that direct consumption coefficient $a_{i j}$ is fixed, there must be a positive and proportional relationship between consumption and production, fixed consumption in production ignored.

Despite exceeding the bounds of reasonable stipulations, these three hypotheses, presented in the forms subject to some ideal conditions, are fundamental in describing more general economic production relations and expanding the scope of input-output method, thus helpful for other researches as well.

\section{Estimation Models of Associated, Indirect, and Complete Economic Effects}

\subsection{Estimation Models of Associated Economic Effects}

(1) Direct Interdependency. The direct interdependency means the economic and technological relation between an industry and another industry which needs products or services from the former. It is usually measured by the direct distribution coefficient $h_{i j}(i, j=1,2, \ldots, n) . h_{i j}$ represents the proportion of the products or services directly used as intermediate products distributed from industry $i$ to industry $j$ in the total output. The formula calculating $h_{i j}$ is

$$
h_{i j}=\frac{x_{i j}}{X_{i}}, \quad(i=1,2, \ldots, n, j=1,2, \ldots, n),
$$

where $x_{i j}$ denotes the products or services used as intermediate products distributed from industry $i$ to the latter and $X_{i}$ is the total output of industry $i$. 


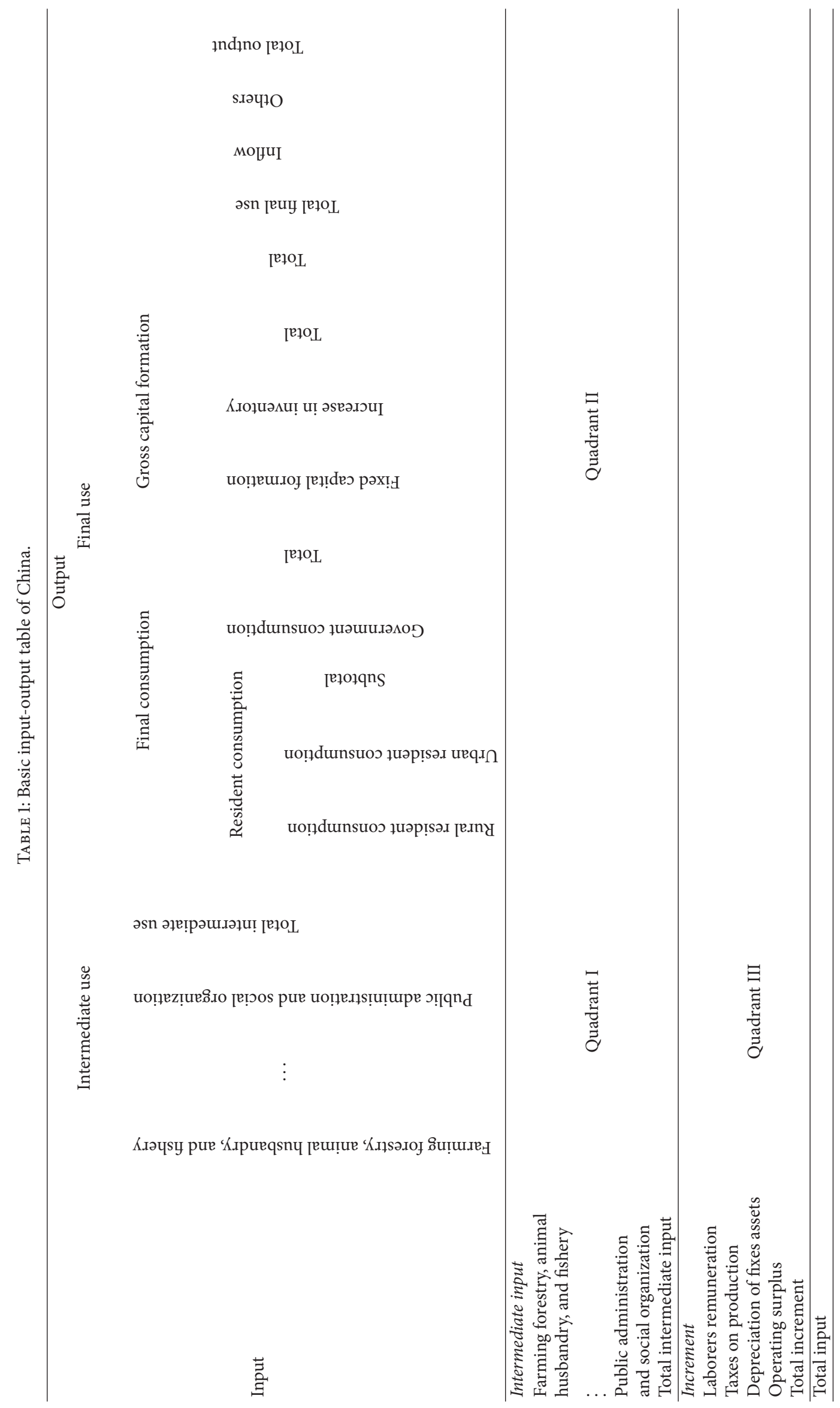


Clearly, the higher the direct distribution coefficient of an industry to another, the greater the direct interdependency of the former industry for the latter industry, and the more obvious direct driving effect.

(2) Complete Distribution Coefficient. The complete distribution coefficient $d_{i j}(i, j=1,2, \ldots, n)$ is the complete distribution of industry $j$ provided per unit of value-added in industry $i$. It can be calculated on the basis of complete consumption coefficient. The matrix form formula calculating $d_{i j}$ is given by

$$
D=(I-H)^{-1}-I,
$$

where $I$ is the $n$ by $n$ identity matrix and $H$ is the matrix of direct distribution coefficients, that is, $H=\left(h_{i j}\right) .(I-H)^{-1}$ describes the total accumulative distribution effect and it is similar to the Leontief inverse matrix $(I-A)^{-1}$.

The bigger the complete distribution coefficient, the greater the motivational effect of complete supply, and the bigger the complete interdependency between industries. Complete distribution coefficients not only reflect the direct impact among industries but also reflect the indirect impact of every level, which is more comprehensive for analyzing relativity between industries.

(3) Associated Economic Effect. The associated contribution is the added value created by the service effect of an industry for the production of intermediate input. According to the balance relation of the input-output table and the theory of industry interdependency, the associated contribution of industry $i$ for the national economy is

$$
E_{i}=\sum d_{i j} Y_{i j}
$$

Here, $d_{i j}$ is the complete distribution coefficient of industry $i$ for products of industry $j, Y_{i j}$ is the direct economic effect of meteorological service for industry $j$ due to industry $i$, and $E_{i}$ in (7) is called the associated economic effect of meteorological service from industry $i$.

3.2. Estimation Model of Indirect Economic Effect. Recall, from Section 2.1, that the indirect economic effect is the economic effect brought indirectly through an economic and technological relation. According to the input-output model in Table 1, we can get the total output of one industry as follows:

$$
\sum_{j=1}^{n} X_{i j}+Y_{i}=X_{i}, \quad(i=1,2, \ldots, n) .
$$

Here, $X_{i j}$ is the intermediate consumption, representing the product value consumed in industry $j$ which is provided by industry $i, Y_{i}$ is the product value which is used as final use in industry $i$, and $X_{i}$ is the total output of industry $i$. By adding the direct consumption coefficients $a_{i j}=x_{i j} / X_{j}$ into the model, (8) can be turned into

$$
\sum_{j=1}^{n} a_{i j} X_{j}+Y_{i}=X_{i}, \quad(i=1,2, \ldots, n) .
$$

The matrix form of (9) is $A X+Y=X$, where $A$ is the technical coefficient matrix, and we have

$$
X=(1-A)^{-1} Y .
$$

In the input-output table, service effects can be represented as the increase of final output, assuming that the final outputs of other industries are fixed. On the basis of the direct economic effect of a certain industry produced by services, we will explain the indirect effect as $\Delta X$ brought by the direct economic effect of an industry. Accordingly, (10) changes into the incremental form:

$$
\Delta X=(I-A)^{-1} \Delta Y .
$$

Here, $\Delta X$ is the indirect effect of this industry brought by meteorological services, $(I-A)^{-1}$ is the Leontief inverse matrix, and $\Delta Y$ is the direct effect of this industry brought by services which is represented as the increase of final use.

3.3. Estimation Model of Complete Economic Effect. According to the previously established estimation model for the indirect economic effect, the increment of final use brought by the direct effect in the first round is $\Delta X=(I-A)^{-1} \Delta Y$.

The increase of output in the first round will improve resident income, thus increasing resident consumption, which will further lead to the increase of output in the second round. The whole process repeats itself in circle. Of course, there are some hidden assumptions. First, the economic system has an enormous amount of idle productive capacity so that there will not be induced investment in the process of circulation. Second, with the increasing resident income, the marginal propensity to consume is constant. Third, consumption structure does not change as consumption scale changes.

Assume that $\alpha=\left(\alpha_{1}, \alpha_{2}, \ldots, \alpha_{n}\right)$ denotes the vector of resident income structure in each industry $\left(\alpha_{i}\right.$ is the ratio of laborers' remuneration in total output for industry i). Let $c$ denote the marginal propensity to consume. Then $c \alpha \cdot(I-A)^{-1} \Delta Y$ represents the increment for consumption brought by service effect in the first round. Let $w$ be the column vector of resident consumption structure coefficient in input-output table. Element $w_{i}$ in $w$ is the ratio of consumption of each industry in the total value of that column. So $w c \alpha(I-A)^{-1} \Delta Y$ is the resident consumption increment produced by the increase of final use in the first round. $(I-A)^{-1} w c \alpha(I-A)^{-1} \Delta Y$ is the output increment induced by the increase of final use in the initial state and first round, and so on. This production-consumption-production cycle will go on until the system reaches a new equilibrium. The foregoing is expressed by a mathematical equation as follows:

$$
\begin{aligned}
\Delta X= & (I-A)^{-1} \Delta Y+(I-A)^{-1} w c \alpha(I-A)^{-1} \Delta Y \\
& +(I-A)^{-1} w c \alpha(I-A)^{-1} w c \alpha(I-A)^{-1} \Delta Y+\cdots
\end{aligned}
$$

Then we can get

$$
\Delta X=(I-A)^{-1}\left[I-w c \alpha(I-A)^{-1}\right]^{-1} \Delta Y .
$$




\section{The Empirical Analysis of Meteorological Service Effects in Jiangxi Province}

In this section, we will utilize the data obtained from Jiangxi province in 2007 to illustrate the concepts and models introduced in this paper (Section 3). We employ the input-output method to estimate the economic effects of meteorological services based on the data given in the 2007 input-output table of Jiangxi [17].

4.1. Sample and Data. Zou et al. conducted a research on the evaluation reports of meteorological services in Jiangxi from 2003 to 2007 using the traditional expert investigation method (Delphi method) [14], while our purpose is, by utilizing the input-output model for the data supplied with the 2007 input-output table of Jiangxi, to estimate quantitatively the economic effects rescued from the preventive strategies that are established based on the meteorological information and the interdependency between industrial economic systems. Our setting of the study is different from that of Zou et al. as outlined below.

(1) Data of Input-Output. They are from "Input-output table of Jiangxi in 2007" and "Input-output table of China in 2007," where the latter was compiled by the Economic Accounting Department of the National Bureau of Statistics of China in 2007. The table involves 2 branch classifications; one is a table of 42 industries and, the other, a table of 135 industries. In this paper we use the data of 135 industries. According to the research of $\mathrm{Gu}$ et al., the resident marginal propensity to consume $c$ in 2007 was 0.66 [18].

(2) Data on the Direct Economic Effect of Meteorological Services. Using the expert investigation method, Zou et al. estimated the meteorological service effect on agriculture, forestry, husbandry, and fishery, transportation, construction, production, and supply of electric power, gas, and water, and insurance, manufacturing, resident service, and other services, wholesale and retail sale in Jiangxi province [14]. To correspond to the names of 135 industries in input-output table, we process the same data but utilizing our comprehensive economic effect estimation method as follows.

(a) Zou, Lu, and Dong synthesized agriculture, forestry, husbandry, and fishery into one industry. In this paper we split it equally into five shares with the same average proportions of $3.61 \%$.

(b) In Zou, Lu, and Dong's study, there was only an average proportion of direct service effect for general "manufacturing". In this paper we use 54 kinds of manufacturing in the table of 135 industries with the same proportions of $0.512 \%$.

(c) In Zou, Lu, and Dong's study, there was only an average proportion of "insurance." Considering that "insurance" is a subkey of "finance" in the table of 135 industries, we equate "insurance" with "finance," whose ratio of meteorological service effect in total output is $1.943 \%$. (d) In Zou, Lu, and Dong's study, there was only an average proportion of "transportation and warehousing." In this paper we treat 8 subkeys of "transportation and warehousing" in the table of 135 industries whose proportions are all $2.454 \%$ equally.

(e) In Zou, Lu, and Dong's study, there was only a contribution rate of "resident service and other services." According to the table of 135 industries, "resident service and other services" will be subdivided into "resident service" and "other services," whose proportions are all $0.484 \%$.

Specific results are provided in Table 2 .

It should be pointed out that the Delphi method is a structured communication technique, originally developed as a systematic, interactive forecasting method which relies on a panel of experts and thus subject to and dependent on the knowledge of the participating experts. Hence, this method is more subjective in nature.

Moreover, since the available meteorological service data sets for Jiangxi province from 2003 to 2007 are quite rich, the input-output method would be more appropriate. In fact, the Delphi (expert opinion) method is utilized only when there is a lack of sufficient information (due to its three drawbacks stated in Section 1).

In contrast, our estimation model (input-output method) for obtaining quantitative results regarding the comprehensive economic effects of meteorological services is established on the inhesion relevance among different industries, which is more objective and provides a practical setting for preventive strategies and other recommendations to rescue in the face of extreme weather conditions.

Specifically, since the input-output table reflects more accurately the technical and economic relationships between industries in the national economy [13], it has become an ideal tool for calculating the associated and indirect economic effects of industries. According to the principle of doing certain things and refraining from doing other things, we present assessment models for associated, indirect, and complete economic effects based on the input-output table. Taking the meteorological service data in Jiangxi province in 2007 as an example, we obtained a series of results regarding the economic effects of meteorological services.

4.2. Results and Analysis. By utilizing the estimation equations of associated economic effect (7), indirect economic effect (11), and complete economic effect (13), we summarize the results in Table 3 .

An analysis of Table 3 reaches the following conclusions.

(1) Due to the technical and economic relations between industries, the direct economic effect of services can bring to all industries the associated, indirect, and complete economic effects. The direct economic effect of meteorological service in Jiangxi province in 2007 was 13882.63853 million RMB, which brought the associated economic effect of 39521.90571 $\mathrm{RMB}$, indirect economic effect of 33991.28942 RMB, and complete economic effect of 50105.33474 RMB. Three economic effects, respectively, increased by 1.847-fold, 1.448-fold, and 2.609-fold. 
TABLE 2: Contribution rate of weather service in highly sensitive industries in Jiangxi province, China (Measuring unit: \%).

\begin{tabular}{|c|c|c|}
\hline Industry & $\begin{array}{l}\text { Direct service effect } \\
\text { in } 2003-2007\end{array}$ & $\begin{array}{l}\text { Contribution rate of } \\
\text { meteorological service } \\
\text { effect }\end{array}$ \\
\hline Agriculture & $4.07-3.15$ & 3.61 \\
\hline Forestry & $4.07-3.15$ & 3.61 \\
\hline Animal husbandry & $4.07-3.15$ & 3.61 \\
\hline Fishery & $4.07-3.15$ & 3.61 \\
\hline Agriculture, forestry, husbandry, and fishery & $4.07-3.15$ & 3.61 \\
\hline Convenience food manufacturing & $0.631-0.392$ & 0.512 \\
\hline Milk and dairy manufacturing & $0.631-0.392$ & 0.512 \\
\hline Condiments and fermentation products manufacturing & $0.631-0.392$ & 0.512 \\
\hline Other food manufacturing & $0.631-0.392$ & 0.512 \\
\hline Alcohol and wine manufacturing & $0.631-0.392$ & 0.512 \\
\hline Textile product manufacturing & $0.631-0.392$ & 0.512 \\
\hline Knitwear, weaving, and its product manufacturing & $0.631-0.392$ & 0.512 \\
\hline Textile wearing apparel, footware, and cap manufacturing & $0.631-0.392$ & 0.512 \\
\hline Furniture manufacturing & $0.631-0.392$ & 0.512 \\
\hline Sport, cultural, and educational supply manufacturing & $0.631-0.392$ & 0.512 \\
\hline Basic chemical raw material manufacturing & $0.631-0.392$ & 0.512 \\
\hline Fertilizer manufacturing & $0.631-0.392$ & 0.512 \\
\hline Pesticide manufacturing & $0.631-0.392$ & 0.512 \\
\hline Coating, printing ink, paint, and similar product manufacturing & $0.631-0.392$ & 0.512 \\
\hline Synthetic material manufacturing & $0.631-0.392$ & 0.512 \\
\hline Special chemical product manufacturing & $0.631-0.392$ & 0.512 \\
\hline Daily chemical product manufacturing & $0.631-0.392$ & 0.512 \\
\hline Pharmaceutical manufacturing & $0.631-0.392$ & 0.512 \\
\hline Chemical fiber manufacturing & $0.631-0.392$ & 0.512 \\
\hline Cement, lime, and gypsum manufacturing & $0.631-0.392$ & 0.512 \\
\hline Cement and gypsum product manufacturing & $0.631-0.392$ & 0.512 \\
\hline Brick, stone, and other building material manufacturing & $0.631-0.392$ & 0.512 \\
\hline Glass and glassware manufacturing & $0.631-0.392$ & 0.512 \\
\hline Ceramic product manufacturing & $0.631-0.392$ & 0.512 \\
\hline Refractory product manufacturing & $0.631-0.392$ & 0.512 \\
\hline Graphite and other nonmetallic mineral product manufacturing & $0.631-0.392$ & 0.512 \\
\hline Nonferrous metal and alloy manufacturing & $0.631-0.392$ & 0.512 \\
\hline Boiler and prime mover manufacturing & $0.631-0.392$ & 0.512 \\
\hline Metalworking machinery manufacturing & $0.631-0.392$ & 0.512 \\
\hline Hoist-transportation machine manufacturing & $0.631-0.392$ & 0.512 \\
\hline Pumps, valves, compressors, and similar machinery manufacturing & $0.631-0.392$ & 0.512 \\
\hline Other common equipment manufacturing & $0.631-0.392$ & 0.512 \\
\hline Mining, metallurgy, and building equipment manufacturing & $0.631-0.392$ & 0.512 \\
\hline Chemical, wood, and nonmetal processing equipment manufacturing & $0.631-0.392$ & 0.512 \\
\hline Special machinery for agriculture, forestry, husbandry, and fishery manufacturing & $0.631-0.392$ & 0.512 \\
\hline Other specialized equipment manufacturing & $0.631-0.392$ & 0.512 \\
\hline Railway transport equipment manufacturing & $0.631-0.392$ & 0.512 \\
\hline Automobile manufacturing & $0.631-0.392$ & 0.512 \\
\hline
\end{tabular}


TABle 2: Continued.

\begin{tabular}{|c|c|c|}
\hline Industry & $\begin{array}{l}\text { Direct service effect } \\
\text { in } 2003-2007\end{array}$ & $\begin{array}{c}\text { Contribution rate of } \\
\text { meteorological service } \\
\text { effect }\end{array}$ \\
\hline Vessel and floating facility manufacturing & $0.631-0.392$ & 0.512 \\
\hline Other transportation equipment manufacturing & $0.631-0.392$ & 0.512 \\
\hline Motor manufacturing & $0.631-0.392$ & 0.512 \\
\hline Transmission and distribution and control equipment manufacturing & $0.631-0.392$ & 0.512 \\
\hline Wire, cable, fiber optic cable, and electrical equipment manufacturing & $0.631-0.392$ & 0.512 \\
\hline Household electric and nonelectric appliance manufacturing & $0.631-0.392$ & 0.512 \\
\hline Other electrical machinery and equipment manufacturing & $0.631-0.392$ & 0.512 \\
\hline Communication equipment manufacturing & $0.631-0.392$ & 0.512 \\
\hline Radar and radio equipment manufacturing & $0.631-0.392$ & 0.512 \\
\hline Electronic computer manufacturing & $0.631-0.392$ & 0.512 \\
\hline Electronic component manufacturing & $0.631-0.392$ & 0.512 \\
\hline Home audio-visual equipment manufacturing & $0.631-0.392$ & 0.512 \\
\hline Other electronic equipment manufacturing & $0.631-0.392$ & 0.512 \\
\hline Instrument manufacturing & $0.631-0.392$ & 0.512 \\
\hline Cultural and office machinery manufacturing & $0.631-0.392$ & 0.512 \\
\hline Craft and other product manufacturing & $0.631-0.392$ & 0.512 \\
\hline Production and supply of power and heat & $2.323-1.569$ & 1.946 \\
\hline Production and supply of gas & $2.323-1.569$ & 1.946 \\
\hline Production and supply of water & $2.323-1.569$ & 1.946 \\
\hline Construction & $2.513-1.769$ & 2.141 \\
\hline Railway transportation & $2.993-1.914$ & 2.454 \\
\hline Road transportation & $2.993-1.914$ & 2.454 \\
\hline City's public transportation & $2.993-1.914$ & 2.454 \\
\hline Water transportation & $2.993-1.914$ & 2.454 \\
\hline Air transportation & $2.993-1.914$ & 2.454 \\
\hline Pipeline transportation & $2.993-1.914$ & 2.454 \\
\hline Handling and other transport service & $2.993-1.914$ & 2.454 \\
\hline Warehousing & $2.993-1.914$ & 2.454 \\
\hline Wholesale and retail sale & $0.44-0.15$ & 0.295 \\
\hline Insurance & $2.279-1.607$ & 1.943 \\
\hline Resident service & $0.655-0.312$ & 0.484 \\
\hline Other service & $0.655-0.312$ & 0.484 \\
\hline
\end{tabular}

Data source: Zou et al. [14].

The ratio range of input in associated economic effect in Jiangxi province is about $1: 85.41-1: 145.197$, the ratio range of input in indirect economic effect is about $1: 73.44-1: 124.848$, and the ratio range of input in complete economic effect is about $1: 108.27-1: 183.059$, which are remarkably different from a previous estimation based on the Delphi method (stated below).

Ren studied the "Input-output table of China in 2007" for the whole country using the traditional Delphi method and concluded that the effect ratio range of input in output brought by meteorological services in China is 1:30-1:51 [19].
In contrast, our results suggest that the associated, indirect and complete economic effects brought by meteorological services are so huge that more attention should be paid to this field.

(2) As observed from the calculation of associated economic effect brought by direct economic effect, the top five industries, in order of decreasing proportions of associated effect are refractory product manufacturing (1405.538fold), special machinery for agriculture, forestry, husbandry, and fishery manufacturing (158.467-fold), cement and gypsum product manufacturing (157.029-fold), brick, stone, and 
TABLE 3: Results of economic effects (measuring unit: ten thousand RMB).

\begin{tabular}{|c|c|c|c|c|}
\hline Industry & $\begin{array}{c}\text { Direct service } \\
\text { effect }\end{array}$ & $\begin{array}{c}\text { Associated } \\
\text { economic effect }\end{array}$ & $\begin{array}{l}\text { Indirect economic } \\
\text { effect }\end{array}$ & $\begin{array}{c}\text { Complete } \\
\text { economic effect }\end{array}$ \\
\hline Agriculture & 224274.860 & 32254.572 & 307400.052 & 415246.092 \\
\hline Forestry & 45652.060 & 67369.404 & 68169.407 & 80815.325 \\
\hline Animal husbandry & 157244.380 & 13094.821 & 180582.946 & 245308.922 \\
\hline Fishery & 65774.200 & 2730.388 & 69725.861 & 80974.323 \\
\hline Service of agriculture, forestry, husbandry, and fishery & 22176.230 & 36522.675 & 31415.316 & 34289.819 \\
\hline Coal mining and washing & 1 & 29468.833 & 64986.176 & 106900.696 \\
\hline Oil and gas exploration & l & 2002.814 & 59147.069 & 96862.943 \\
\hline Ferrous metal ore mining & l & 3.147 & 15374.575 & 17790.070 \\
\hline Nonferrous metal mining & l & 6192.810 & 27888.475 & 35079.747 \\
\hline Other nonmetal ore mining & l & 180479.691 & 27467.146 & 31787.500 \\
\hline Grain grinding & l & 40438.204 & 8231.043 & 22338.272 \\
\hline Feed processing & l & 76422.147 & 29632.467 & 39312.748 \\
\hline Vegetable oil processing & l & 7223.678 & 3069.876 & 11041.238 \\
\hline Sugar industry & l & 354.072 & 11.208 & 86.284 \\
\hline Slaughtering and meat processing & l & 4688.495 & 3631.551 & 16511.096 \\
\hline Aquatic product processing & l & 886.262 & 1136.525 & 6718.374 \\
\hline Other food processing & 1 & 603.799 & 1374.011 & 16120.633 \\
\hline Convenience food manufacturing & 1294.285 & 188.289 & 1363.028 & 7520.514 \\
\hline Milk and dairy manufacturing & 541.542 & 175.256 & 716.447 & 4223.064 \\
\hline Condiments and fermentation products manufacturing & 1733.750 & 595.822 & 2805.411 & 5249.706 \\
\hline Other food manufacturing & 4296.243 & 129.679 & 4683.159 & 25718.227 \\
\hline Alcohol and wine manufacturing & 3949.839 & 742.590 & 6565.676 & 20779.630 \\
\hline Soft drink and refined tea processing & l & 368.611 & 729.371 & 3786.235 \\
\hline Tobacco processing & l & 90.931 & 205.572 & 14109.853 \\
\hline $\begin{array}{l}\text { Cotton, chemical fiber textile and printing, and dyeing } \\
\text { finishing }\end{array}$ & / & 2263.104 & 11392.778 & 36670.132 \\
\hline Weaving, dyeing, and finishing & l & 424.478 & 308.375 & 5435.661 \\
\hline Linen textile, silk spinning, and finishing & 1 & 1519.773 & 2792.121 & 7674.866 \\
\hline Textile product manufacturing & 2318.879 & 11662.786 & 7111.676 & 12948.707 \\
\hline Knitwear, weaving, and its product manufacturing & 3286.149 & 1361.131 & 4670.416 & 7287.079 \\
\hline $\begin{array}{l}\text { Textile wearing apparel, footware, and cap } \\
\text { manufacturing }\end{array}$ & 7537.976 & 18570.466 & 19011.769 & 43126.773 \\
\hline $\begin{array}{l}\text { Leather, fur, feathers (fine hair), and its product } \\
\text { manufacturing }\end{array}$ & l & 1591.953 & 9140.069 & 30904.725 \\
\hline $\begin{array}{l}\text { Timber, wood, bamboo, rattan, palm, and straw } \\
\text { processing }\end{array}$ & l & 51003.512 & 23097.462 & 38102.199 \\
\hline Furniture manufacturing & 7927.270 & 13202.959 & 11774.138 & 20665.662 \\
\hline Paper and paper product manufacturing & l & 3417.195 & 20861.898 & 45138.795 \\
\hline Printing and copying for recording medium & 1 & 2752.207 & 4972.889 & 17553.695 \\
\hline Sport, cultural, and educational supply manufacturing & 5552.497 & 12173.136 & 14409.494 & 22219.404 \\
\hline Oil and nuclear fuel processing & 1 & 53732.201 & 45330.912 & 74672.808 \\
\hline Coking & / & 134.923 & 30533.565 & 35546.660 \\
\hline Basic chemical raw material manufacturing & 4313.508 & 7067.420 & 27771.611 & 37444.661 \\
\hline Fertilizer manufacturing & 4776.596 & 113030.519 & 46324.485 & 60428.552 \\
\hline
\end{tabular}


TABle 3: Continued.

\begin{tabular}{|c|c|c|c|c|}
\hline Industry & $\begin{array}{c}\text { Direct service } \\
\text { effect }\end{array}$ & $\begin{array}{c}\text { Associated } \\
\text { economic effect }\end{array}$ & $\begin{array}{c}\text { Indirect economic } \\
\text { effect }\end{array}$ & $\begin{array}{c}\text { Complete } \\
\text { economic effect }\end{array}$ \\
\hline Pesticide manufacturing & 3479.818 & 123788.558 & 30955.208 & 40371.197 \\
\hline $\begin{array}{l}\text { Coating, printing ink, paint, and similar product } \\
\text { manufacturing }\end{array}$ & 2246.195 & 73507.519 & 12012.993 & 16516.688 \\
\hline Synthetic material manufacturing & 4390.088 & 8384.865 & 20399.731 & 28660.573 \\
\hline Special chemical product manufacturing & 5617.388 & 5959.214 & 32088.072 & 44742.483 \\
\hline Daily chemical product manufacturing & 5380.403 & 3648.736 & 8484.226 & 20895.037 \\
\hline Pharmaceutical manufacturing & 14668.068 & 4186.108 & 22027.422 & 29524.215 \\
\hline Chemical fiber manufacturing & 5324.564 & 9295.692 & 13389.803 & 19345.855 \\
\hline Rubber product manufacturing & 1 & 36257.879 & 16756.519 & 26013.082 \\
\hline Plastic product manufacturing & l & 67906.036 & 19624.883 & 38499.650 \\
\hline Cement, lime, and gypsum manufacturing & 8157.829 & 185923.581 & 40322.398 & 49618.238 \\
\hline Cement and gypsum product manufacturing & 1465.631 & 230146.363 & 7133.046 & 7690.405 \\
\hline Brick, stone, and other building material manufacturing & 934.492 & 144240.892 & 4230.565 & 7271.283 \\
\hline Glass and glassware manufacturing & 3514.849 & 36133.173 & 16109.635 & 22741.921 \\
\hline Ceramic product manufacturing & 1071.437 & 116648.089 & 3055.160 & 4717.192 \\
\hline Refractory product manufacturing & 23.347 & 32815.366 & 108.039 & 121.212 \\
\hline $\begin{array}{l}\text { Graphite and other nonmetallic mineral product } \\
\text { manufacturing }\end{array}$ & 1815.357 & 23832.294 & 5177.474 & 6063.783 \\
\hline Ironmaking & l & 123.489 & 2086.748 & 2427.965 \\
\hline Steelmaking & l & 92.345 & 9490.169 & 11074.714 \\
\hline Steel rolling processing & l & 253850.953 & 192794.942 & 223013.850 \\
\hline Ferroalloy smelting & l & 915.104 & 8348.284 & 9723.447 \\
\hline Nonferrous metal and alloy manufacturing & 15380.644 & 8219.925 & 59352.409 & 72456.541 \\
\hline Nonferrous metal rolling process & 1 & 16988.377 & 35441.068 & 45998.841 \\
\hline Metal product manufacturing & 1 & 46209.909 & 18022.247 & 31824.760 \\
\hline Boiler and prime mover manufacturing & 1585.843 & 15390.963 & 5216.272 & 6956.593 \\
\hline Metalworking machinery manufacturing & 1317.524 & 8476.230 & 4777.305 & 6708.909 \\
\hline Hoist-transportation machine manufacturing & 751.089 & 560.301 & 1799.648 & 2400.930 \\
\hline $\begin{array}{l}\text { Pumps, valves, compressors, and similar machinery } \\
\text { manufacturing }\end{array}$ & 747.080 & 18494.049 & 3112.927 & 4196.952 \\
\hline Other common equipment manufacturing & 2549.709 & 33004.312 & 15292.951 & 19117.583 \\
\hline $\begin{array}{l}\text { Mining, metallurgy, and building equipment } \\
\text { manufacturing }\end{array}$ & 1225.585 & 34734.644 & 5878.842 & 7334.650 \\
\hline $\begin{array}{l}\text { Chemical, wood, and nonmetal processing equipment } \\
\text { manufacturing }\end{array}$ & 153.743 & 1372.453 & 594.162 & 828.217 \\
\hline $\begin{array}{l}\text { Special machinery for agriculture, forestry, husbandry, } \\
\text { and fishery manufacturing }\end{array}$ & 542.986 & 86045.197 & 5151.476 & 6327.882 \\
\hline Other specialized equipment manufacturing & 10897.859 & 7327.467 & 47018.932 & 66889.403 \\
\hline Railway transport equipment manufacturing & 186.199 & 18862.441 & 3037.940 & 4247.180 \\
\hline Automobile manufacturing & 6337.792 & 31957.175 & 31643.484 & 46873.349 \\
\hline Vessel and floating facility manufacturing & 2552.346 & 5227.158 & 4394.514 & 5606.492 \\
\hline Other transportation equipment manufacturing & 2430.771 & 535.248 & 2891.412 & 6278.044 \\
\hline Motor manufacturing & 2773.806 & 27926.379 & 13458.015 & 17086.261 \\
\hline $\begin{array}{l}\text { Transmission, distribution, and control equipment } \\
\text { manufacturing }\end{array}$ & 1124.588 & 54310.877 & 6471.885 & 8334.190 \\
\hline
\end{tabular}


TABle 3: Continued.

\begin{tabular}{|c|c|c|c|c|}
\hline Industry & $\begin{array}{l}\text { Direct service } \\
\text { effect }\end{array}$ & $\begin{array}{c}\text { Associated } \\
\text { economic effect }\end{array}$ & $\begin{array}{l}\text { Indirect economic } \\
\text { effect }\end{array}$ & $\begin{array}{c}\text { Complete } \\
\text { economic effect }\end{array}$ \\
\hline $\begin{array}{l}\text { Wire, cable, fiber optic cable, and electrical equipment } \\
\text { manufacturing }\end{array}$ & 4094.003 & 114155.168 & 16208.657 & 21175.912 \\
\hline $\begin{array}{l}\text { Household electric and nonelectric appliance } \\
\text { manufacturing }\end{array}$ & 4924.380 & 23225.400 & 7882.982 & 17166.417 \\
\hline $\begin{array}{l}\text { Other electrical machinery and equipment } \\
\text { manufacturing }\end{array}$ & 10017.357 & 14318.681 & 21735.315 & 27076.277 \\
\hline Communication equipment manufacturing & 2352.241 & 2951.962 & 4628.916 & 10437.479 \\
\hline Radar and radio equipment manufacturing & 181.233 & 1602.207 & 281.370 & 326.689 \\
\hline Electronic computer manufacturing & 1193.221 & 17732.838 & 4494.400 & 9978.567 \\
\hline Electronic component manufacturing & 5151.759 & 6807.819 & 17136.031 & 27029.060 \\
\hline Home audio-visual equipment manufacturing & 3591.788 & 1461.821 & 4379.862 & 20785.160 \\
\hline Other electronic equipment manufacturing & 871.793 & 6197.221 & 1338.956 & 1758.516 \\
\hline Instrument manufacturing & 3068.764 & 9233.189 & 12540.223 & 17682.669 \\
\hline Cultural and office machinery manufacturing & 603.192 & 48454.565 & 2153.542 & 3659.179 \\
\hline Craft and other product manufacturing & 3195.546 & 66736.291 & 11051.372 & 16906.321 \\
\hline Scrap waste & 1 & 236.007 & 330.902 & 416.647 \\
\hline Production and supply of power and heat & 86655.828 & 26555.778 & 232416.262 & 384403.028 \\
\hline Production and supply of gas & 830.203 & 2633.266 & 1794.680 & 3742.844 \\
\hline Production and supply of water & 7733.696 & 37911.991 & 12831.484 & 21718.429 \\
\hline Construction & 384517.177 & 783.857 & 398017.605 & 411185.018 \\
\hline Railway transportation & 44262.798 & 34882.827 & 139320.673 & 198323.547 \\
\hline Road transportation & 100498.662 & 54551.412 & 180734.309 & 225390.320 \\
\hline City's public transportation & 8640.534 & 20198.200 & 12884.220 & 16904.497 \\
\hline Water transportation & 2287.128 & 14447.927 & 4474.668 & 7291.585 \\
\hline Air transportation & 3791.430 & 19799.388 & 7387.494 & 11854.599 \\
\hline Pipeline transportation & 1 & 0.000 & 0.000 & 0.000 \\
\hline Handling and other transport service & 1992.648 & 10219.544 & 3805.300 & 5947.536 \\
\hline Warehousing & 2736.210 & 9417.221 & 3598.809 & 4164.856 \\
\hline The postal service & 1 & 22052.628 & 2228.910 & 4591.521 \\
\hline $\begin{array}{l}\text { Telecommunication and information transmission } \\
\text { service }\end{array}$ & l & 12765.332 & 12776.421 & 39300.447 \\
\hline Computer service & l & 2211.991 & 1412.032 & 2692.011 \\
\hline Software & 1 & 517.298 & 70.752 & 184.895 \\
\hline Wholesale and retail sale & 28363.365 & 33103.282 & 171367.334 & 286838.534 \\
\hline Accommodation & 1 & 20236.829 & 7528.296 & 16449.092 \\
\hline Catering & / & 22786.509 & 25574.979 & 49250.285 \\
\hline Banking, security, and other financial activity & l & 33651.299 & 46885.264 & 82681.399 \\
\hline Insurance & l & 38477.101 & 5864.920 & 11096.667 \\
\hline Real estate & I & 6902.654 & 18166.860 & 78204.631 \\
\hline Leasing & I & 118605.765 & 835.384 & 2422.092 \\
\hline Business service & l & 15666.721 & 6283.722 & 10785.177 \\
\hline Tourism & I & 74.551 & 128.804 & 3505.748 \\
\hline Research and experimental development & l & 117186.760 & 1598.279 & 1857.017 \\
\hline Professional and technical service & 1 & 136052.891 & 4321.458 & 5614.004 \\
\hline
\end{tabular}


TABle 3: Continued.

\begin{tabular}{|c|c|c|c|c|}
\hline Industry & $\begin{array}{l}\text { Direct service } \\
\text { effect }\end{array}$ & $\begin{array}{c}\text { Associated } \\
\text { economic effect }\end{array}$ & $\begin{array}{l}\text { Indirect economic } \\
\text { effect }\end{array}$ & $\begin{array}{c}\text { Complete } \\
\text { economic effect }\end{array}$ \\
\hline $\begin{array}{l}\text { Science and technology exchange and promotion } \\
\text { service }\end{array}$ & I & 20825.614 & 803.687 & 1126.383 \\
\hline Geological exploration & I & 0.000 & 0.000 & 0.000 \\
\hline Water management & / & 115937.570 & 2979.632 & 4471.497 \\
\hline Environmental management & I & 9469.365 & 1190.529 & 2282.958 \\
\hline Public facilities management & l & 523.006 & 110.174 & 1655.620 \\
\hline Resident service & 2045.384 & 13369.132 & 5267.168 & 13544.352 \\
\hline Other service & 3366.220 & 26964.684 & 20683.657 & 33635.381 \\
\hline Education & l & 2670.063 & 8415.407 & 33121.785 \\
\hline Health & l & 3211.955 & 15980.637 & 33957.909 \\
\hline Social security & / & 7518.737 & 82.898 & 106.042 \\
\hline Social welfare & / & 4109.687 & 92.954 & 114.111 \\
\hline Press and publication & / & 30820.604 & 2182.198 & 4817.494 \\
\hline Radio, television, film, and motion picture & l & 158.709 & 148.309 & 1230.560 \\
\hline Culture and art & l & 23.727 & 0.957 & 553.198 \\
\hline Sport & / & 0.000 & 0.000 & 109.717 \\
\hline Entertainment & l & 18301.346 & 4832.876 & 8490.062 \\
\hline Public management and social organization & 1 & 3246.067 & 5919.578 & 7626.480 \\
\hline Total & 1388263.853 & 3952190.571 & 3399128.942 & 5010533.474 \\
\hline
\end{tabular}

other building material manufacturing (154.352-fold), and ceramic product manufacturing (108.871-fold). The bottom five are construction (0.002-fold), other food manufacturing (0.030-fold), fishery (0.042-fold), animal husbandry (0.083fold), and agriculture (0.144-fold).

Also, from the calculation of indirect economic effect brought by direct economic effect, the top 5 industries in order of decreasing increments are railway transport equipment manufacturing (15.316-fold), fertilizer manufacturing (8.698-fold), special machinery for agriculture, forestry, husbandry, and fishery manufacturing (8.487-fold), pesticide manufacturing (7.896-fold), and basic chemical raw material manufacturing (5.438-fold). The bottom five construction (0.035-fold), convenience food manufacturing (0.053-fold), fishery (0.060-fold), other food manufacturing (0.090-fold), and animal husbandry (0.148-fold).

Furthermore, as observed from the calculation of complete economic effect brought by direct economic effect, the top 5 industries in order of decreasing increments are railway transport equipment manufacturing (21.810-fold), fertilizer manufacturing (12.1651-fold), special machinery for agriculture, forestry, husbandry, and fishery manufacturing (10.654fold), pesticide manufacturing (10.602-fold), and wholesale and retail sale (9.113-fold). The bottom five are construction (0.069), fishery (0.231), warehousing (0.522-fold), service of agriculture, forestry, husbandry, and fishery (0.546-fold), and animal husbandry (0.560-fold).

Thus, increments of indirect and complete economic effects on traditional meteorological service objects such as construction, agriculture, forestry, husbandry, fishery, and warehousing are comparatively low, while some industries such as railway transport, equipment manufacturing, and fertilizer manufacturing can reach more indirect and complete economic effects. Consequently, in the future, meteorological service should tilt toward industries including railway transport, equipment manufacturing, and special machinery for agriculture, forestry, husbandry, and fishery manufacturing and provide more targeted fine services to improve their indirect and complete economic effects of meteorological service.

(3) As seen from the calculation of complete economic effect brought by indirect economic effect, the top five industries in order of decreasing increments are culture and art (577.222-fold), tobacco processing (67.673-fold), tourism (26.218-fold), weaving, dyeing, and finishing (16.627-fold), and public facilities management (14.027-fold). The bottom six are construction (0.033-fold), cement and gypsum product manufacturing (0.078-fold), service of agriculture, forestry, husbandry, and fishery (0.092-fold), refractory product manufacturing $(0.122$-fold $)$, steel rolling processing (0.157-fold), and ferrous metal ore mining ( 0.157 -fold). It indicates that owing to the production-consumption-production cyclic effect, the output multipliers of industries like culture and art, tobacco processing, and tourism are bigger than those of construction, agriculture, forestry, husbandry, fishery, and so on. The results are of course affected by multiple factors such as technical and economic relation, marginal propensity to consume, ratio of resident income in total output, and so on. Because of the increasing relevance of industrial economic system, rapid development of public administration, social organization, education, technology, and the gradual reveal of effect on the policies of expanding 
domestic demand, the indirect and complete economic effects brought by meteorological service will continue to increase.

While Zou, Lu, and Dong estimated the ratio of meteorological services effect (input-output ratio) for various industries, they did not calculate the economic effects [14]. As a result, we could not make a comparison between our results and theirs.

\section{Concluding Remarks}

In this paper we introduced the concepts of direct (associated, indirect, and complete) economic effect. Focusing our research on the direct consuming coefficient, the complete consuming coefficient, and Leontief inverse matrix, we have developed estimation methods for the associated, indirect, and complete economic effects. Using the meteorological services in Jiangxi province as a demonstrative example, the concepts and methods have been validated.

The main findings include the following.

(1) Higher interdependency between economic systems of different industries exist, implying that the associated, indirect, and complete economic effects brought on by meteorological services could be much larger. For example, the ratio range of input in complete economic effect on meteorological services in Jiangxi province is about $1: 108.27-1: 183.059$, which is larger than that of previous estimation using Delphi method (1:30-1:51), suggesting that the society as a whole should pay more attention to meteorological services.

(2) Some industries with higher industrial connection ratios (Leontief inverse matrix), such as steel rolling processing, other nonmetal ore mining, and manufacturing, can achieve more associated, indirect, and complete economic effects. It follows that more attention should be paid to the meteorological services of these industries.

(3) Increments of complete economic effect for some industries are relatively larger. These include railway transport, equipment manufacturing, fertilizer manufacturing, special agriculture machinery manufacturing, forestry, livestock, and fishery manufacturing, pesticide manufacturing, wholesale and retail sales, and other services. Consequently, governments should engage meteorological services in these areas.

(4) Increments of indirect and complete economic effects on meteorological services traditionally directed to industries like construction, agriculture, forestry, livestock, and fishery, and warehousing are low. In the future, meteorological service providers should both expand their customer range and improve their quality of service in order to ultimately increase their comprehensive economic effects in these domains.

The algorithms developed in this paper are characterized by the following strengths.
(1) When used in estimating the economic effects of meteorological services, the algorithms make it possible to fully consider the intrinsic relationship between industries; calculated comprehensive values are more scientific and credible.

(2) The algorithms developed can rank the industries with the biggest increments and pick out highly sensitive industries. The results can provide references for development strategy and meteorological service investment decisions.

(3) The algorithms can also be used for loss from weather events, for example, for the associated, indirect, and complete economic loss of industrial economic systems caused by disasters or sudden crises (e.g., the impact estimation of "911" event on US aviation). Similarly, the impact estimation for different carbon reduction policies on industrial economic systems, goal programming, and design of industrial regulations, all lend themselves to the use of the algorithms.

Finally, there are still some concerns regarding the concepts, algorithms, and applications of associated, indirect, and complete economic effect estimation mentioned. In particular, the assumption that the relevance within industries is linear, rigid, and static may not reflect exactly reality of dynamic and complex industrial economic systems. To overcome such constraints assumed in the input-output method remains a major focus of future research.

\section{Conflict of Interests}

The authors declare that there is no conflict of interests regarding the publication of this paper.

\section{Acknowledgments}

This research was supported by the Natural Science Foundation of China (71373131, 71140014, and 11371292), National Social and Scientific Fund Program (11CGL100), National Soft Scientific Fund Program (2011GXQ4B025), and National Industry-specific Topics (GYHY200806017). This research was also supported by the Priority Academic Program Development of Jiangsu Higher Education Institutions.

\section{References}

[1] L. S. Prokopy, T. Haigh, A. S. Mase et al., "Agricultural Advisors: a receptive audience for weather and climate information, Wea," Climate, and Society, vol. 5, no. 2, pp. 162-167, 2013.

[2] A. P. R. Pery, G. Schuurmann, P. Ciffroy et al., "Perspectives for integrating human and environmental risk assessment and synergies with socio-economic analysis," Science of the Total Environment, no. 456-457, Article ID 316, pp. 456-307, 2013.

[3] T. Nguyen, J. Robinson, S. Kaneko, and S. Komatsu, "Estimating the value of economic effects associated with adaptation to climate change in a developing country: a case study of improvements in tropical cyclone warning services," Ecological Economics, vol. 86, pp. 117-128, 2013. 
[4] E. Birol, K. Karousakis, and P. Koundouri, "Using economic valuation techniques to inform water resources management: a survey and critical appraisal of available techniques and an application," Science of the Total Environment, vol. 365, no. 1-3, pp. 105-122, 2006.

[5] A. M. Krieger and P. E. Green, "A decision support model for selecting product/service benefit positionings", European Journal of Operational Research, vol. 142, no. 1, pp. 187-202, 2002.

[6] X. Xu, Qixiang Fuwu Xiaoyi Pinggu Fangfa Yu Fenxi Yanjiu, China Meteorological Press, 2009.

[7] H. Kan and B. Chen, "Particulate air pollution in urban areas of Shanghai, China: health-based economic assessment," Science of the Total Environment, vol. 322, no. 1-3, pp. 71-79, 2004.

[8] H. Chen and L. Yin, "Calculation of Indirect and complete economic effects," Journal of UEST of China, vol. 21, no. 3, pp. 339-344, 1992.

[9] H. Wang, "The computation of the forward and backward complete economic efficiency," Systems Engineering, vol. 6, no. 4, pp. 53-56, 1998.

[10] G. J. D. Hewings and M. Sonis, "Input-output analysis," International Encyclopedia of Human Geography, pp. 491-498, 2009.

[11] T. A. Chen, T. C. Chang, W. Y. Chiau, and Y. C. Shih, "Social economic assessment of coastal area Industrial development: an application of input-output model to Oyster Farming in Taiwan," Ocean and Coastal Management, vol. 73, pp. 153-159, 2013.

[12] C. Kerschner and K. Hubacek, "Assessing the suitability of input-output analysis for enhancing our understanding of potential economic effects of Peak Oil," Energy, vol. 34, no. 3, pp. 284-290, 2009.

[13] Y. Zhang and K. Zhao, Regional Input-Output Analysis, Social Science Academic Press, Beijing, China, 2006.

[14] X. Zou, M. Lu, and B. Dong, Meteorological Service Effects Evaluation Report in Jiangxi From 2003-2007, Qixiang Fuwu Xiaoyi Pinggu Wenji, 2008.

[15] Y. Y. Haimes, B. M. Horowitz, J. H. Lambert, J. R. Santos, C. Lian, and K. G. Crowther, "Inoperability input-output model for interdependent infrastructure sectors. I: theory and methodology," Journal of Infrastructure Systems, vol. 11, no. 2, pp. 67-79, 2005.

[16] Z. Chen and X. Zhang, "Research of several methodological issues of input-output analysis," Quantitative \& Technical Economics, vol. 9, pp. 83-90, 2005.

[17] Economic accounting department of national bureau of statistics of China, Input-Output Table of China, China Statistics Press, 2007.

[18] B. Gu, H. Li, and H. Ye, "Changes in urban and rural residents' marginal propensity to consume and the policy implication," Journal of Financial Research, vol. 3, pp. 199-206, 2009.

[19] Z. Ren, Evaluation method research of meteorological service effect [Ph.D. Dissertation], Nanjing University of Information Science \& Technology, 2009. 